\title{
ON AN IMPROVED CONSTRUCTION OF TOOL FOR TURNING METALS AT INCREASED SPEED.
}

\author{
By Colonel Clay, of Liverpool.
}

Many improvements have been made from time to time in the Tools and appliances for turning and shaping metals; the tools have been duplicated and multiplied in special cases, and improved forms have been introduced with more or less success; but as far as the writer is aware no attempts have been made to increase the efficiency of the individual tool by increasing its speed of working. His attention was drawn to the subject by a question being raised as to the reason why the speed is limited to the very slow rate in universal use, and whether the operation of turning and shaping metals could not be considerably accelerated beyond a surface speed of about 10 to 15 feet per minute, which is the practical limit in this class of work. The objection to an increase of speed is that the cutting tool would become heated, and would consequently lose its temper and utility; for it is kept cool by water dropping upon the work from a can and delivery tube placed just over the tool, and an increase in the quantity of water supplied would fail to cool it sufficiently at a higher speed of working, because very little if any of the water actually comes in contact with the cutting edge, the water being guarded from it by the shaving of metal, upon the upper surface of which it is delivered, as illustrated in Fig. 1, Plate 77.

It occurred to the writer that if the water conld be supplied direct to the cutting edge itself, and in sufficient quantity to carry off all the heat liberated by the operation of turning, the speed of the operation might at once be increased very considerably, without any difference in the condition of the tool from that existing with the ordinary slow speed. This object ho 
succeeded in effecting by means of the tool shown in Figs. 2 and 3, Plate 77. A hole is drilled throughout the length of the cutting portion of the tool $T$, to the bottom end of which is connected the india-rubber tube A from the ordinary water can. The upper end of the hole terminates near the cutting point of the tool, and a constant jet of water is delivered from it, and is discharged on the underside of the shaving that is being cut off, and plays upon the point of the tool so effectually as to keep it thoroughly cool when the speed of surface is increased many times beyond the ordinary limit.

In Figs. 4 and 5 is shown a modification of the "plan for application to a heavy turning tool having a wide cutting edge. In this case a hole $B$ is drilled into the tool longitudinally near the upper surface, and a transverse hole drilled into it at the inner end, which has a short nipple screwed in for the purpose of attaching the india-rubber feed tube $A$ from the water can. The front end of the longitudinal hole is stopped by a wood plug, and three small oblique holes are drilled down into it from the upper face of the tool, terminating near the cutting edge; by this means a constant supply of water is maintained, flowing over the whole of the cutting edge to keep it cool.

The upper portion of the holes in each of the tools is drilled very small, about $\frac{1}{8}$ inch diameter, to prevent weakening the tool; but the body of the hole can be made any size that is convenient. No inconvenience in working is involved, as the ordinary water can is used, and the india-rubber tube has simply to be slipped upon the nipple or the tool end. It is not necessary for the tool to be drilled at all for the purpose, as the water can be applied as effectually by an external jet, provided that the jet plays upon the same place, between the point or edge of the cutter and the under surface of the shaving that is being cut off; the drilled hole in the tool is adopted as a convenient mode of applying the jet.

The speed at which wrought iron can be turned is generally considered to be limited to from 15 to 20 feet per minute, but in practice this speed is seldom obtained, the actual speed 
of work being from 10 to 15 or an average of about 13 feet per minute. With the hollow tool the speed has been increased to 60 feet per minute, or four times the ordinary speed, with heavy cuts in a 12 inch lathe; and with light cuts has been further increased to 110 feet per minute, or eight times the ordinary speed, the tool keeping quite cool and working well at that high speed. When it is considered that the time required for getting through a piece of work in the lathe is determined directly by the speed, the practical value of any increase in the ordinary speed will be seen to be very considerable, both in saving time with a job, and in getting so much more work out of each lathe in the same time.

Colonel Clay exhibited specimens of the turning tools described in the paper, and remarked that it was not material whether the water was supplied through a hole in the tool itself, as in the specimens exhibited, or by a separate external jet; the only object was that a sufficient supply of water should be delivered on the cutting edge itself of the tool, to keep it cool in working. Trials had been made of the hollow tool at some of the principal engineering works in London, the speed of the lathes being increased by throwing out the back gear and driving with single gear; but the driving belts slipped before the limit of speed that the tool would stand had been reached. The tool tried was one of the ordinary round tools of Messrs. Smith and Coventry's make, of the size usually employed for a 12 inch lathe. The larger tool shown in the drawings, with the wide cutting edge, had been tried at the Birkenhead Iron Works, turning off a shaving 1-16th inch thick from a shaft 8 inches diameter at a surface speed of 95 feet per minute; and a screw shaft 11 inches diameter and 20 feet long had also 
been turned by the tool at the speed of 27 feet per minute. From 15 to 20 feet was the speed usually spoken of with the ordinary tools, but in practice be had generally found the speed actually attained in regular work did not exceed from 10 to 14 feet per minute, according to the rate of traverse employed. The plan of making the round cutter bear with a small shoulder in the toolholder, as shown in Fig. 2, Plate 77, for enabling it to take very heavy cuts without slipping, was an improvement intended to meet the objection frequently felt to attempting a heavy cut, on the ground that the set-screws ordinarily employed for fixing the cutter in the holder were not sufficient to prevent it from slipping under a heavy cut. When the cutter had been ground down it could be set up again to the proper height by simply inserting a washer of the required thickness in the socket in the toolholder, underneath the shoulder of the cutter. For securing the cutter in the toolholder he employed a small taper steel pin with a flat side (C, Figs. 2 and 3), driven in transversely so as to jam the cutter in its socket; this he considered would be found much more convenient than the ordinary set-screws, particularly in shops where these tools with separate cutter and holder were not in regular use, because it frequently happened that the special box-spanner required for the set-screws got mislaid, and some time was lost in looking for it when it was wanted; but with the taper pin anything would do for knocking it out or tightening it up, so that there would never be the slightest difficulty or delay in removing or fixing the cutter. The object of the improved tool was to give increased facilities for turning and shaping metals in a quicker manner than had hitherto been practicable; and whatever increase in speed of work might be obtained with the new tools, he was satisfied that some benefit would result from showing that even with existing tools more work could be done than had usually been obtained.

Mr. W. Fond SMite said he had made a few experiments with the new hollow cutter, bat not for a sufficient length of time to determine the quantity of work done by it as compared with that 
done by the ordinary cutter in the same time. With an ordinary solid cutter he had turned small shafts of $1 \frac{1}{2}$ inch diameter at a cutting speed of 30 feet per minute, making 20 revolutions to each 1 inch of traverse; and with the hollow cutter cooled by the water the speed had been increased to 47 feet per minnte; the cutter in that instance was inverted in the lathe, so as to cut downwards instead of upwards. The quantity of work done in a given length of time however, though rather more than that got through with the ordinary cutter, was not in that instance proportionate to the increase of speed, because a good deal of time was lost at starting, in consequence of its being impracticable to start the lathe at once at the high speed; it had accordingly been necessary to start at first with the slower speed, and afterwards to throw on the high speed. Further experience was therefore desirable in regard to the relative quantity of work done. $\mathrm{He}$ had not himself met with any diffeulty from the entter getting pushed down in the toolholder in taking a heavy cut, when held only by set-screws; in turning a Bessemer steel shaft of 7 inches diameter with $\frac{1}{2}$ inch depth of cut and $\frac{3}{8}$ inch traverse per revolution, he had not found the cutter slip, though secured only by the set-screws which were not tightened up more severely than usual; the cutter in this case was held by two steel setscrews with hardened ringed ends.

The President observed that the superiority of the hollow tool seemed to be attributed simply to the cooling effect of the water upon the cutting edge of the tool; and he suggested that part of the adrantage might be attributable to the cutting edge being also lubricated by the water jet. This conld not take place in the ordinary arrangement, where the water was thrown off by the shaving and did not get to the cutting edge of the tool; but with the hollow tool the water jet would not only cool the cutting edge but also lubricate it.

Colonel Clay said the object he had had in view had been simply to bring the cooling action of the water as near as possible to the cutting edge of the tool; and for the purpose of more effectually accomplishing this object one plan tried had been 
to cut a shallow groove in the upper face of the tool, immediately behind the cutting edge and parallel to it, and communicating by a channel with the water hole in the tool, Fig. 6, Plate 77, so as to make sure of the water getting as close up to the cutting edge as possible, and to avoid the risk of its being prevented from doing so by the shaving ever getting in the way. The trials at present made with the hollow tool had all been made with plain water, not soap and water; but the lubrication of the cutting edge was no doubt an important matter, and it would be well for further experiments to be tried in reference to the suggestion now made upon that point. Another matter which had not yet been sufficiently attended to in the trials of the new tools was the proper angle of the cutting edge, and he did not know whether the angle had been made to agree exactly with that which was found the best in the ordinary tools. There could be no question however as to the very important increase of speed, which caused the shavings of metal to fly off in a small lathe just like shavings of wood; in some of the trials he had made, the speed had been as much as 110 feet per minute in taking a finishing cut.

The President considered the improved tool was a very simple and efficient contrivance, and likely to meet with very general adoption. He proposed a vote of thanks to Colonel Clay for his paper, which was passed.

The Meeting then terminated. 
HOLLOW TURNINC TOOL.

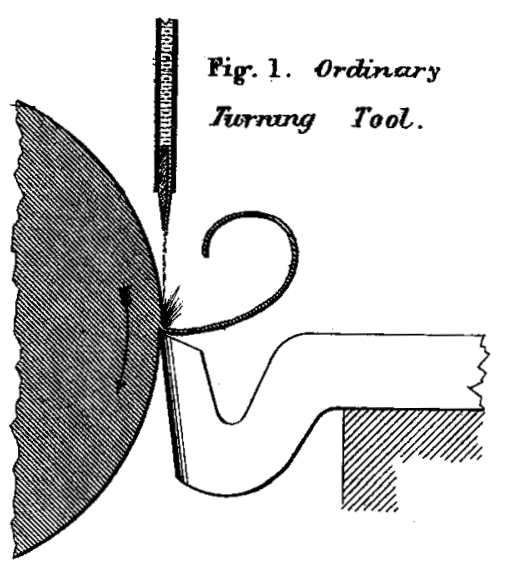

Fig. 6.

Fig. 2. Improved

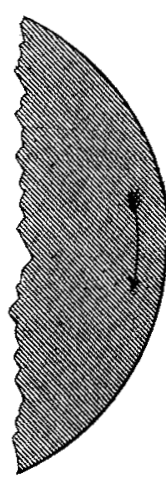

Hollow rool

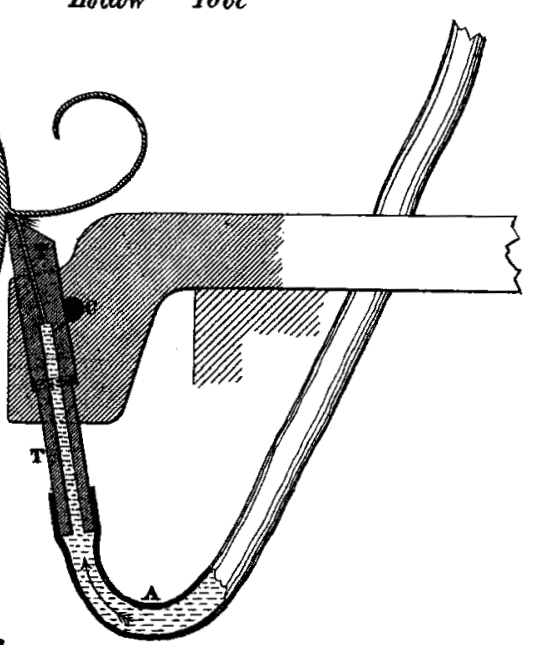

$\Theta$

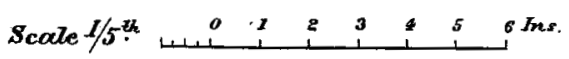

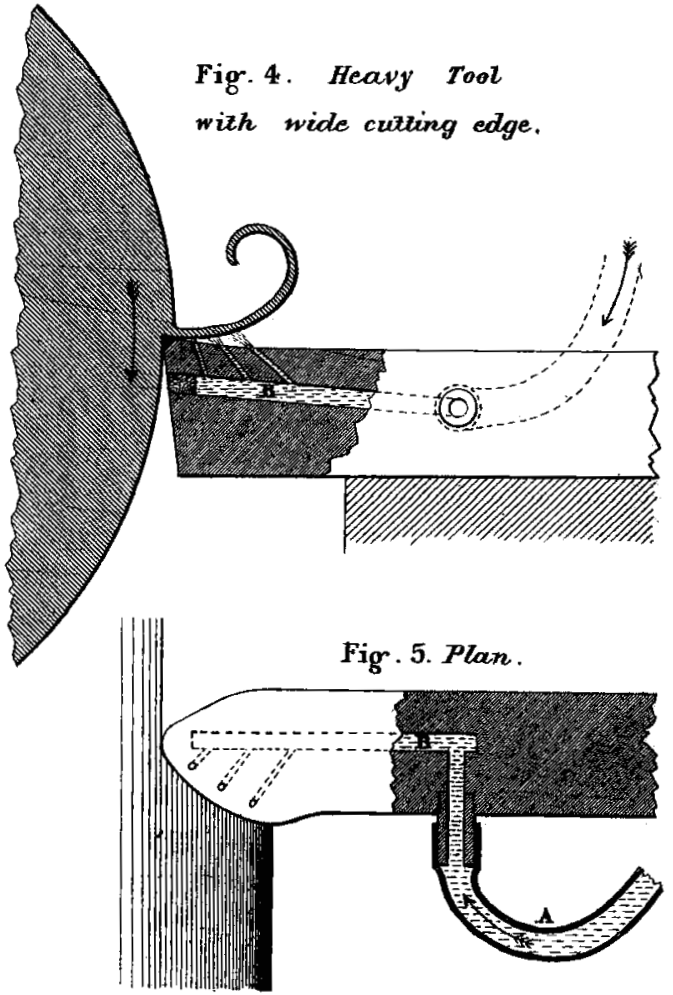

